\title{
A Review on the prevalence of Hepatitis B Virus (HBV) among pregnant women in Makurdi, Benue State, Nigeria 2008
}

\author{
Ayanleke Halimatu Bolatito*1, Manyara Ibuuri Marete ${ }^{2}$, Mohammed Yahaya ${ }^{3}$ \\ ${ }^{1}$ Atlantic International University, College of Human and Social Sciences, Honolulu ,Hawaii, USA \\ ${ }^{2}$ Institute of Business Studies, Nairobi , Kenya \\ ${ }^{3}$ Department of Microbiology, Usmanu Danfiodyo University Teaching Hospital, Sokoto State, Nigeria
}

*Corresponding author: Ayanleke Halimatu Bolatito, Atlantic International University, Honolulu, Hawaii, USA

\section{ARTICLE INFO}

Received: 紪 February 19, 2019

Published: 櫘 February 26, 2019

Citation: Ayanleke Halimatu Bolatito. A Review on the prevalence of Hepatitis B Virus (HBV) among pregnant women in Makurdi, Benue State, Nigeria 2008. Biomed J Sci \& Tech Res 15(2)-2019. BJSTR. MS.ID.002662.

\begin{abstract}
The pervasiveness of hepatitis B virus (HBV) and its infectivity condition among expectant women in Nigeria has been on the higher edge thus requiring intervention. An article written by Mbaawauaga and other four scholars focusing on "hepatitis B virus (HBV) infection among expectant women in Makurdi, Nigeria" concluded that there was an endemicity of HBV illness in the area and that the illness is likely to be acquired via both vertical and horizontal means of transmission. The study made use of 300 women as the populace under study using random anonymous testing of volunteers who had attended the antenatal clinics. The study suggested that all expectant ladies should undergo screening and immunization which should be free. Both ladies and infants should be placed in the antenatal and post natal programs to enhance eradication of HBV infection.
\end{abstract}

Keywords: Hepatitis B Virus (HBV); Prevalence; Vaccination

\section{Aim}

The risk that is paused by HBV to pregnant women and unborn babies is of public health importance. For several years, Nigeria has been among the few countries where the disease has proved endemic. Very many people who live in Nigeria have been infected without their knowledge. As a result, many fail to seek suitable medical attention, thus leading to chronic illnesses. There are areas without enough information about this issue which have led to insufficient information on control and prevention strategies. The main aim of this study is to generate data from the Nigerian local context which will help the policy makers come up with appropriate programs and strategies that can help in reducing the prevalence of the disease. It is important if both the health workers, policy makers and the general public understand about this whole issue if an affirmative action will be taken.

\section{General Objective}

The main aim of the project is to determine the prevalence of hepatitis B virus carrier in conjunction with the infectivity condition of carrier expectant women.

\section{Specific Objectives:}

a) To establish the prevalence of HBV infection among pregnant women in Nigeria

b) To determine the main means of transmission through which the illness is acquired

c) To establish ways through which the disease can be eradicated or reduced amongst pregnant women in Nigeria

\section{Introduction}

"Hepatitis B Virus (HBV) infection among Pregnant Women in Makurdi, Nigeria" is an article written by Mbaawuaga, Okopi and two others with an aim of determining the prevalence of hepatitis B virus carrier together with infectivity condition of carrier expectant women [1]. The research took place in Makurdi where data was gathered to offer information on its deterrence and control approaches. Based on the article, Hepatitis B is one of the main and ordinary infectious illness of the liver and its everywhere in the world. The disease is as a result of a little enclosed DNA virus 
known as the Hepatitis B virus (HBV) [1]. When the virus was initially discovered in a patient blood, it was known as the Australia antigen but later it was renamed to Hepatitis B Surface Antigen (HBsAg). Sometimes later, bacteria were branded as a marker for sick people who were at a high risk for transmission of the diseases [1]. Data on this disease indicate that approximately two billion individuals are affected by HBV worldwide and more than 350 people have it as a chronic infection. Study indicates that after a pregnant woman gets infected with the disease, there are chances that she will infect her fetus.

Reports shows that $10-20 \%$ of those ladies who are seropositive for HBsAg tend to pass on the virus to their un-born, but the women who happens to be seropositive to both HBeAg and HBsAg, their vertical transmission happen to be approximately 90\% [2]. Scholars have defined chronic HBV as a carriage of HBsAg for the first six months and it is the highest risk which is $80-90 \%$ of chronic illness have been discovered in the infected neonates who happens to be born to mothers who are HBeAg positive carriers [2]. Nigeria is considered to be one of the countries where the HBV infection is endemic. The current studies shows that approximately 18 million people living in Nigeria have been infected. Some of these individuals are not even sentient of the virus therefore; they fail to seek suitable medical attention which leads to chronic liver illness, hepatocellular and cirrhosis. More so, when it happens that some of these individuals who have infected by the disease are women, they pose a stern health hazard not only to their unborn kids but also the community at large. Despite that there are places where studies on $\mathrm{HBV}$ are common, there are other places where information is very scant which leads to lack of a course of action and other sufficient information on control and preventive strategies [3].

\section{Materials and Methods}

To find out the pervasiveness of the illness in the area, the following materials and methods were used;

\section{Study Area}

Data was collected in Makurdi metropolis, situated in an area which happens to cover $16 \mathrm{~km} 2$. The area is located in the North central of Nigeria whereby its average yearly rainfall is $1200 \mathrm{~mm}$ and the average yearly utmost temperature is 33.4 degrees Celsius [1]. There are two universities situated in that area and two post secondary institutes and has been gifted with agricultural feasibility which tend draw people from other areas of the country. Other disadvantaged reports indicate that the area has the highest pervasiveness of sexually transmitted illnesses [2].

\section{Selection of Subjects}

Data was collected from all women who happen to attend the antenatal clinics in various hospitals situated at Makurdi metropolis. Nobody was coerced to partake in the research and each of the subjects who were involved in the research was offered consent. The recruitment happened to be through simple random sampling from the month of January to April of the year 2005 [1]. All the subjects involved happened to be 300 who were from the age 10 to 49 years and to accredit the data collection process, an endorsement was gotten from the ethical commission of Benue State Ministry of health and Human services in Makurdi.

\section{Variables}

Various questions were indicated in a structured questionnaire where most of the things which were being asked include; age, profession, marital status, sex during menstrual phase, herbal medicine utilization, smoking and alcoholic utilization. Those who were engaged in the research were questioned on whether they had previously suffered from arthritis and their blood groups together with the Packed Cell Volume (PCV) were checked.

\section{Collection of Sample/Analysis}

From every patient, five milliliter blood sample was obtained using venopuncture. One milliliter of the blood was introduced into an EDTA can for PCV together with ABO blood grouping. The remaining blood was put into a uncontaminated test tube, given a chance to clot in a natural mode and separated using a centrifugal at 1,500 cycles per minute. A section of the sera collected was used in testing for Hepatitis B Surface Antigen (HBsAg) through the use of latex speedy agglutination slide test kits [1]. These entire tests were carried out in the health centers where the samples had been collected. All the reactive samples happened to be stored at a -20 degrees Celsius and they were used to confirm further for HBsAg with the use of commercially available enzyme linked immunesorbent assay kit.

\section{Statistical Analysis}

Outcomes which had all been collected were all put under the statistical analysis with the use of Statistical Package for Social Sciences (SPSS) version 11. After the statistical analysis, a comparison proportion was done with the use of chi-square test where the p-values which were less than one were considered significant [1].

\section{Results}

The analysis indicated that out of the 300 subjects, 33 of them or $11 \%$ were seropositive for the infection or the Hepatitis B surface antigen (HBsAg). The infection was at the peak among the young people aged 10-19 years. Ten of the 33 women or $30.3 \%$ were branded as HBV carriers and they all tested positive for HBeAg. Hence $33 \%$ of the whole study populace was positive for HBeAg.

\section{Discussion}

The discussion and categorization of high endemicity from HBV contagion in most cases has been categorized as HBsAg which is larger than $7 \%$ in the adult population. The observed $11 \% \mathrm{HBsAg}$ seropositivity among expectant women in Makurdi is an indication that the area like the rest of Nigeria is prevalent. The prevalence of the disease and the results indicated by this study is similar to other 
studies which had been carried out before [1]. This is a result which even the government confirmed to be true noting that, though it was carried out in a hospital and it was urban based, the figures produced were similar to very many other studies carried out in other places. HBeAg seroprevalence ranging at 3.3\% which was reported among the entire population was an implication that one of every 45 subjects or one of every 3 individuals who were HBV carriers happened to be at high risk of spreading the infection to her un-born as well as had the likelihood of the disease becoming chronic [1]. The figures might be alarming but they tallies with other many results of studies done before. There are indications that also in other countries around the sub-Sahara such as Zimbabwe have similar cases which show that the issue of vertical transmission along these areas cannot be ignored [1].

High frequency of HBV carriers which has been noted among the teenagers who are between 10-19 and other people who are between 30-39 years and also a corresponding high prevalence of HBeAg is an indication that there is high severity of the infection among the communities. The severity might result from anemia which tends to significantly decrease with an increasing age. The pervasiveness can also be associated to effect of oral pills which are likely to be causing a higher dominance of HBeAg among people between the ages of 30-39 years [1]. Oral pills happens to be steroid hormone which are prepared in a tablet appearance and happens to have a slower but longer deed in the body invigorating the immune system for a bigger period of time. These pills have been said to immune-suppress lymphocytes through reduction of the action of T-Lymphocytes and reduces the immunoglobulin secretion. Therefore, anemia and the effects from the oral pills happen to be unanalyzed elements such as malaria and HIV which happens to contribute enormously to the endemicity of HBV infection among expectant women in Nigeria.

In conclusion, this is a study which provided information about the pervasiveness of HBV contagion in Makurdi area in Nigeria. The study suggests that teenage expectant women ought to be seriously monitored to prevent anemia from spreading. Immunization and free screening of all pregnant women and their young ones ought to be included in the antenatal and post-natal programs in a hospital aiming at preventing post-natal infection of the babies by their infected mothers.

\section{References}

1. Aba H O, Aminu M (2016) Seroprevalence of hepatitis B virus serological markers among pregnant Nigerian women. Annals of African medicine 15(1): 20 .

2. Mbaawuaga EM, Enenebeaku M, Okopi J (2008) Hepatitis B virus (HBV) infection among pregnant women in Makurdi, Nigeria. African Journal of Biomedical Research 11(2).

3. Musa BM, Bussell S, Borodo MM, Samail AA, Femi OL, et al. (2015) Prevalence of hepatitis B virus infection in Nigeria, 2000-2013: a systematic review and meta-analysis. Nigerian journal of clinical practice 18(2): 163-172.s
ISSN: 2574-1241

DOI: 10.26717/BJSTR.2019.15.002662

Ayanleke Halimatu Bolatito. Biomed J Sci \& Tech Res

CC (i) This work is licensed under Creative

Submission Link: https://biomedres.us/submit-manuscript.php

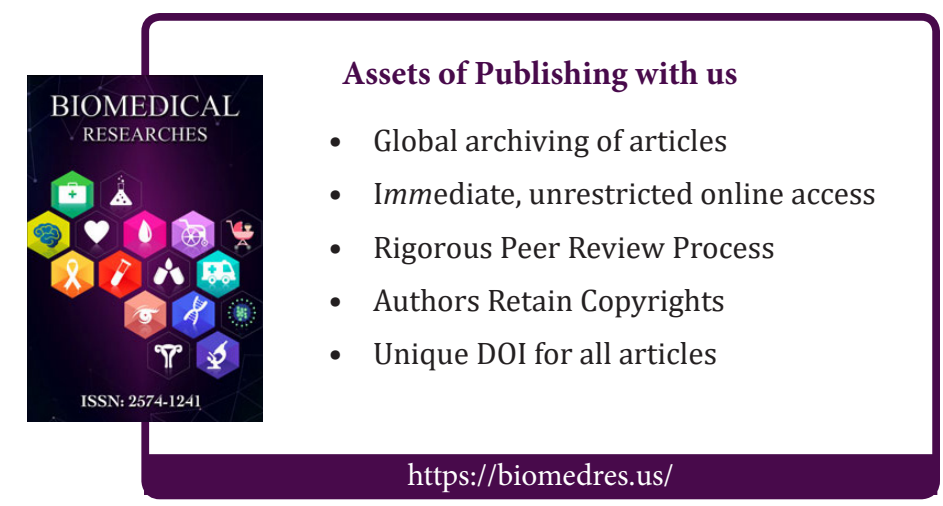

